\title{
A DISTRIBUIÇĀO GEO-POLÍTICA DAS UNIDADES DE TERAPIA INTENSIVA NO BRASIL
}

\author{
Cilene Aparecida Costardi Ide* \\ Eliane Corrêa Chaves*
}

IDE, C.A.C. \& CHAVES, E.C. A distribuição geo-política das unidades de terapia intensiva no Brasil. Rev. Esc. Enf. USP, São Paulo, 23(3):193-204, dez. 1989.

A partir da recomposição da trajetória evolutiva do processo de institucionalizaçâo das práticas de saúde no Brasil, as autoras analisam a dimensão assumida pelo arcabouço institucional, salientando a inserção das UTIs nesse contexto.

UNITERMOS: Sistemas de atendimento em saúde. Serviços de saúde - Brasil. Unidades de terapia intensiva.

\section{INTRODUÇĀO}

A análise do aparato político-jurídico do Sistema de Saúde, enquanto arcabouço institucional para o desempenho das práticas de saúde, pressupōe a delimitação de diferentes referenciais analíticos. Implica, preliminarmente, na tentativa de identificar a trajetória evolutiva do processo de institucionalização destas açōes no país localizando, especificamente, a origem e a expansão da assistência intensiva nesse contexto. A compreensão dessa dimensão analítica abrangeria, também, a correlação entre o perfil institucional assumido pelo Sistema de Saúde e o modelo econômico-político-jurídico e ideológico determinante, tanto do processo de expansão e alocação geo-política dos diferentes recursos assistenciais como também, dos distintos perfis de morbimortalidade vigentes. Assim, os horizontes assumidos por esse movimento expressariam como a saúde gravita na sociedade na medida em que corporifica o campo de atuação e as prioridades das políticas de saúde chamadas a "prevenir, suprimir ou manipular as contradições produzidas pela dinâmica social e reconhecidas como problemas ou desvios pelo consenso dos grupos dominantes" ". A partir desse referencial será possível identificar os objetivos e tendências dessa prática frente às concepções de saúde-doença e de assistência que manifestam, implícita ou explicitamente, bem como o espaço peculiar da assistência terciária nessa infra-estrutura.

\footnotetext{
* Enfermeiras, professoras assistentes da Escola de Enfermagem da USP, COREN-SP 9282 e 13.356.
} 
Dando início à proposta deste estudo e recompondo o processo de institucionalização das práticas de saúde no Brasil vale preliminarmente, salientar que esse movimento possuiria especificidades quando comparado ao contexto europeu ou norte-americano.

Nesse sentido, a revoluçāo vital, caracterizada pela queda da mortalidade nos países industrializados, a partir do século 19, foi um processo que não obedeceu à mesma ordem cronológica e nem se completou em plano mundial. Assim, enquanto os países desenvolvidos conquistavam o controle das enfermidades infecto-contagiosas, pela melhoria do padrão alimentar e pelo controle sanitário, já se deparando e se adequando à transformação do quadro nosológico, o país ainda priorizava o controle da afecções com etiologia e patogênese definidas ${ }^{6}$.

O Brasil do início do século correspondia a um país ainda não industrializado, vinculado a um modelo primário-exportador tradicional. Tinha como diretriz assistencial e contenção da doença, identificando nas práticas higienistas um instrumento de controle ambiental e de planejamento urbano, complementada por medidas sanitaristas que tentavam substituir a coerção pelo convencimento. Sob essa tendência, priorizou-se a educação como instrumento capaz de reverter as condições de saúde da população, ao mesmo tempo em que persistiam os projetos fiscalizadores, incluindo o confinamento dos grupos de risco. $\mathrm{O}$ modelo de prática priorizado desempenharia um papel social específico, ou seja, o controle das epidemias através de ações de saúde pública. Esse padrão de desempenho atenderia à política de exportação, pela fiscalização das condições ambientais inclusive dos portos, e à política de imigração, pela avaliação das condiçōes de saúde dos estrangeiros que aqui chegavam.

À derrocada do modelo primário-exportador emerge um novo projeto de política econômica. Este caracterizava-se fundamentalmente pelo processo de substituição de importações, concretizado pela implantação de um parque industrial diversificado. Assim, novas prioridades no atendimento à saúde-doença passam a compor o elenco das práticas assistenciais até entāo voltadas à saúde pública. Frente ao movimento de industrialização, que se expande inclusive para aquém das cidades, frente aoa reordenamento do espaço urbano, onde se agregam contingentes crescentes de imigrantes, frente à organização do movimento operário, que passa a reivindicar acesso à assistência e, mais do que tudo, frente à necessidade de se manter a produtividade no setor industrial, delineia-se nova perspectiva para as ações de saúde. Conseqüentemente, tornam-se prioridades, preliminarmente, a expansão da cobertura institucional desenvolvida em unidades mistas, agregando a asssistência ambulatorial à retaguarda de leitos para pronto-atendimento. Tinham por objetivo, o controle das condições basais de saúde do trabalhador, inclusive do segmento materno-infantil. Posteriormente, esse padrão de prática passa a ser direcionado para o atendimento individual desenvolvido progressivamente no âm- 
bito hospitalar, mantendo, como característica primordial, a alienação frente às condições estruturais determinantes, tanto do processo saúde-doença quanto das diretrizes políticas do Sistema de Saúde.

Somente a partir da década de 40 é que a assistência passa a ter cunho predominantemente individualizado, desenvolvendo-se em instituições hospitalares. O perfil do sistema de saúde, a partir desse período, caracteriza-se pela incorporação dos avanços tecnológicos, pelo aprimoramento dos métodos diagnósticos e terapêuticos, pela absorção dos recursos farmacêuticos e de equipamentos, enfim, pela hospitalização da assistência, consolidando um perfil institucional específico e articulado ao projeto econômico-político vigente. Caracteriza-se, ainda, por um processo de expansão da cobertura assistencial na tentativa de satisfazer, ainda que de maneira limitada e distorcida sob vários aspectos, às diferentes necessidades de atendimento determinadas pela dinâmica social.

Nesse sentido, o desafio assistencial se deslocaria das enfermidades contagiosas para as crônico-degenerativas e, gradativamente, do agente para o hospedeiro e meio ambiente, culminando na concepção sociológica-descritiva do processo saúde-doença. A saúde, nesta vertente, resultaria da relação entre um homem, historicamente localizado, com uma função específica no sistema de produção e a sua inserção num meio natural e social que molda sua atitude face aos sinais de alterações que lhe são dados perceber.

À medida que se modifica o perfil nosológico e a concepção de saúde-doença multiplicam-se as atividades dos serviços de saúde em decorrência de inúmeros fatores, dentre os quais salienta-se: a maior procura desses serviços pelos clientes em busca de atendimentos veiculados como tendo possibilidade ilimitadas de êxito terapêutico; a iatrogênese inerente aos diferentes procedimentos utilizados para satisfazer essa demanda; a invasão pela Medicina de um número cada vez maior de áreas da vida individual tais como o controle da alimentação, da atividade física, do lazer e pela própria incapacidade do sistema em oferecer soluções para as diferentes doenças decorrentes de conflitos no plano interpessoal e social. Tais fatores dariam origem e alimentariam o dinamismo que provoca, tanto a expansão ilimitada do campo de atuação dos serviços de saúde quanto a sua inoperância $e$ obsolescência frente às expectativas dos clientes e dos profissionais do setor ${ }^{4}$.

Esse crescimento tem característica óbvias, ou seja: a sintonia e subordinação aos interesses empresariais das multinacionais vinculadas à saúde; a necessidade de solucionar desvios agudos e diminuir sequelas capazes de limitar a atividade física do trabalhador, minimizando as perdas na produção e consumo e, ainda, a aderência aos interesses das categorias profissionais que viam na sofisticação a soluçāo para todos os males independente do custo, da especificidade e dos resultados questionáveis, caracterizando a vinculação ideológica da política assistencial aos interesses econômicos hegemônicos ${ }^{4}$. 
Nesse contexto as UTIs surgem no Brasil atrasadas já que têm como marco cronológico a década de 70, porém, com o ímpeto e com a mesma finalidade de uma assistência vinculada à tecnologia de ponta, ou seja: "centralizar recursos materiais e humanos numa área hospitalar destinada a receber pacientes graves recuperáveis, que necessitassem de observação constante e de cuidados específicos e de alta complexidade"2.

Entretanto, apesar do aparato, muito poucos foram os avanços nos níveis de saúde da população. Documento elaborado pelo Ministério da Saúde em 1986 evidencia, a partir das últimas décadas, a queda na mortalidade proporcional por doenças infecto-contagiosas e o progressivo aumento desse índice em decorrência das doenças cardiovasculares e câncer, passando de 15 para $40,0 \%$ de todas as causas de óbito. Ainda segundo o referido documento, "os avanços científicos e tecnológicos das últimas décadas no Brasil incorporando novos e poderosos recursos de diagnóstico e tratamento, não modificaram a mortalidade por essas doenças. Cateterismo cardíaco, medicina nuclear, radioterapia, ultrassom, tomografia, novas drogas, cirurgias e transplantes, unidades de terapia intensiva, etc., não foram suficientes para reduzir a mortalidade por doenças não transmissíveis"'. Vivenciase, portanto, um contexto de agudização e potencialização dos perfis de morbimortalidade, com padrōes característicos simultaneamente da modernidade e do atraso, compondo um quadro sanitário complexo e supra-determinado a exigir um novo modelo assistencial.

No Brasil, o atual movimento de organização das práticas de saúde tem como referencial a reforma sanitária proposta na $8^{a}$ Conferência Nacional de Saúde, cujo principal objetivo é a implementação do Sistema Único de Saúde, com expansâo e fortalecimento do setor estatal em níveis federal, estadual e municipal. Esse projeto identifica como meta uma progressiva estatização do setor, a partir do reestabelecimento do poder político, administrativo e financeiro dos Estados e Municípios. Para viabilizar o processo de construção de um novo Sistema Nacional de Saúde, foi instalada em Brasília a Comissão Nacional de Reforma Sanitária, pela Portaria Interministerial MEC/MS/MPAS 02/86, de 20/08/86.

A reforma sanitária, enquanto reorganização do Sistema de Saúde, apoia-se "na premissa de que a saúde é um bem público de responsabilidade do Estado... Esse movimento no sentido de transformação somente poderá se concretizar a partir de ampla reforma de natureza jurídico-institucional que permita, de um lado; redefinir o padrão vigente de relacionamento entre o setor público e o privado, em todas as esferas de abrangência da política de saúde e, de outro lado, superar a atual fragmentação assistencial, garantindo real autonomia aos Estados e Municípios na alocação dos recursos na gestão do sistema, com efetiva participação das entidades representativas dos trabalhadores e da populaçāo"5.

Sob esse prisma, muitas têm sido as propostas de reorganização do Setor, abrangendo desde a fusão dos Ministérios da Saúde e da Previdência e Assistência 
Social, passando pela incorporação do INAMPS pelo M.S. e chegando até as propostas de unificação cuja expressão mais recente é a constituição dos Sistemas Unificados e Descentralizados (SUDS), sob o comando das Secretarias Estaduais de Saúde 5 .

Contudo, apesar da abrangência e coerência da proposta muitos têm sido os obstáculos à sua implantação. Protocolos de intenção, medidas isoladas e atos administrativos estariam sendo desenvolvidos no sentido de torná-lo real. Entretanto, a indefinição na relação público/privado, a inoperância induzida da rede estatal e a política de repasse de verba centralizada em pessoas e inacessível ao controle dos diferentes segmentos sociais, seriam alguns dos fatores a retardar a sua implementação. Apesar das dificuldades, a transição do modelo vigente para um substitutivo pressupōe a definição de um novo arcabouço político-jurídico para o Sistema Nacional de Saúde, enquanto determinante de um processo rumo à unificação institucional, descentralização das açōes de saúde e democratização dessa prática. Da sua implementação dependerá a garantia do acesso de todos aos serviços de saúde já existentes assim como aqueles a serem criados e aprimorados, configurando as metas primordiais da Reforma Sanitária a ser desenvolvida.

É frente a esse referencial que cabe, agora, identificar a forma político-jurídica assumida pelas instituições de saúde no Brasil, explicitando as características de distribuiçāo regional em geral e, especificamente, das UTIs nesse contexto.

\section{A INFRA-ESTRUTURA INSTITUCIONAL: TRAÇOS DE UM PERFIL}

Os dados aqui apresentados foram obtidos a partir de levantamentos estatísticos oficiais ${ }^{3}$. Mesmo assim, cabe, preliminarmente, ressaltar a relatividade dos mesmos em decorrência da própria natureza metodológica adotada e que agrega como categorias semelhantes realidades distintas e heterogêneas. Assim, a dimensão das questôes analisadas tendem a ser simplificadas pois acabam por equacionar as características de uma dada realidade a partir de informaçōes de cunho quantitativo, genericamente categorizadas. Tal procedimento não permitiria, portanto, análises de natureza qualitativa capazes de demonstrar, por exemplo, que a relação de um estabelecimento de saúde para uma determinada proporção de habitantes numa região econômica e socialmente mais desenvolvida não equivale qualitativamente à mesma proporção numa outra realidade geo-política a despeito da equivalência que os dados numéricos possam retratar. Não permitiria, ainda, conhecer a natureza e utilização dos recursos dimensionados na medida em que não explicita a conjuntura na qual estão inseridos. Por outroa lado, categorias consideradas como uniformes tais como "instituições de saúde", "leitos hospitalares", "UTIs", apesar da mesma denominação que aparentemente as identifica podem significar realidades completamente distintas na medida em que se desconhece: as características das mesmas; a dimensão, complexidade e articulação assumi- 
das por cada uma delas; as condiçōes de funcionamento desses recursos; a sua disponibilidade para a população e, mais do que isso, para que tipo de população; qual o perfil de assistência prestada dentre outras características. Assim, torna-se temário comparar leitos hospitalares, estabelecimentos de saúde ou UTIs de um centro urbano desenvolvido com uma realidade rural diametralmente diferente enquanto padrão, tanto de desenvolvimento econômico-social quanto de morbimortalidade vigente, mesmo que estatisticamente tal procedimento seja viável e aponte semelhanças.

A relatividade dos dados a serem apresentados deve-se, também, ao fatc destes terem sido coletados em 1984, ainda que sejam os mais recentes. Deve-se, principalmente, por terem sido estratificados segundo critérios regionais que muito mais que semelhanças geográficas deveriam retratar as condições de desenvolvimento econômico, determinantes do perfil de instituições e práticas de saúde que assumem, assim, uma dimensão geo-política que extrapola contextos territoriais.

Apesar das limitações são estes os dados estatísticos mais atualizados e é esta a metodologia assumida pelo Instituto Brasileiro de Geografia e Estatística (IBGE). Este será, portanto, o referencial estatístico a ser explicitado a seguir.

\section{Tabela 1}

ESTABELECIMENTOS DE SAÚDE POR REGIME DE ATENDIMENTO E CLASSIFICAÇÃO DA ENTIDADE MANTENEDORA, BRASIL-1984

\begin{tabular}{|l|r|r|r|r|r|r|r|}
\hline \multirow{2}{*}{ Regiões } & \multicolumn{6}{|c|}{ Estabelecimentos de Saúde } \\
\cline { 2 - 8 } & Total & \multicolumn{7}{|c|}{ Com Internação } & \multicolumn{3}{|c|}{ Sem Internação } \\
\cline { 2 - 7 } & & \multicolumn{1}{|c|}{ Total } & Público & Privado & Total & Público & Privado \\
\hline & & & & & & & \\
Brasil & 27.552 & 6.861 & 1.547 & 5.314 & 20.691 & 16.816 & 3.875 \\
Norte & 1.593 & 432 & 187 & 245 & 1.161 & 1.078 & 83 \\
Nordeste & 8.384 & 1.902 & 794 & 1.108 & 6.482 & 5.840 & 642 \\
Sudeste & 10.982 & 2.484 & 347 & 2.137 & 8.498 & 6.070 & 2.428 \\
Sul & 4.860 & 1.297 & 135 & 1.162 & 3.563 & 2.923 & 640 \\
Centro-Oeste & 1.733 & 746 & 84 & 662 & 987 & 905 & 82 \\
\hline
\end{tabular}

Fonte: Estatísticas de Saúde, Assistência Médico-Sanitária, v.9 1984 p. 4-5. 


\section{Tabela 2}

\section{POPULAÇÃO ESTIMADA E NÚMERO DE LEITOS SEGUNDO AS REGIÖES, BRASIL, 1984}

\begin{tabular}{|l|c|c|c|}
\hline Regiōes & População estimada & No leitos gerais & Relação população/leito \\
\hline & & & \\
Brasil & 132.658 .700 & 538.721 & $1 / 246$ \\
Norte & 7.289 .900 & 17.570 & $1 / 414$ \\
Nordeste & 38.297 .900 & 98.435 & $1 / 389$ \\
Sudeste & 57.841 .300 & 288.469 & $1 / 200$ \\
Sul & 20.430 .100 & 97.333 & $1 / 209$ \\
Centro-Oeste & 8.799 .500 & 36.914 & $1 / 238$ \\
\hline
\end{tabular}

Fonte: Estatística de Saúde, Assistência Medico-Sanitária, v.9. 1984 p.15.

Os dados levantados pelo $\mathrm{IBGE}^{3}$ e mostrados nas tabelas 1 e 2 retratam importante precariedade de recursos institucionais ligados à saúde em todo território nacional. Eles demonstram preliminarmente que, em termos gerais e com base unicamente no montante de estabelecimentos de saúde, a alocação de recursos privilegia a regiāo sudeste, seguida pela nordeste, decrescendo significativamente nas regiōes Norte e Centro-Oeste (tabela 1). Pode-se considerar, portanto, que a lógica e os interesses do capital se mantém na medida em que os recursos disponíveis se concentram na regiāo Sudeste para os quais se voltam os interesses econômicos propulsorès do desenvolvimento dos serviços de saúde. Entretanto, ao analisar-se a tabela 2, nota-se que esses dados tornam-se relativos quando se articula o número total de estabelecimentos de saúde das diferentes regiōes brasileiras com outras variáveis tais como: extensōes territoriais, características das instituiçōes (englobando número de leitos, número de atendimentos diários, entidade mantenedora, insumos e tipo de assistência que prestam); característica da população (incluindo a dimensão demográfica, perfil de morbi-mortalidade e o respectivo perfil reprodutivo determinante, inclusive, do acesso a esses serviços). Embora não dispondo de dados que agreguem esse contexto, pode-se inferir que uma das características primordiais do serviço de Saúde seja a de contribuir para acentuar a defasagem entre recursos disponiveis para a assistência à saúde e a demanda por atendimento em seus diferentes níveis.

Considerando o tipo de estabelecimento de saúde, detecta-se que em todas as regiōes prevalecem as instituições parahospitalares, incluindo desde os postos de saúde até os ambulatórios gerais e especializados. 
Se por um lado esses dados determinam uma característica positiva no sentido de explicitar uma certa ênfase à assistência primária, por outro lado evidenciam uma realidade preocupante pois, segundo dados do $\mathrm{IBGE}^{3}, 43,3 \%$ destas instituições referem-se exclusivamente a postos de saúde, ou seja, unidades destinadas à prestação básica de assistência com utilização de técnicas simplificadas executadas por pessoas de nível elementar ou médio, mas que muitas vezes prestam assistência de saúde numa esfera de competência que extrapola inclusive o âmbito da enfermagem. Vale salientar, ainda, que os postos de saúde representam 78,5\% dos estabelecimentos sem internação da região norte e $61,8 \%$ da região Nordeste, confirmando, no âmbito assistencial a característica de subdesenvolvimento economicamente determinada. Nas demais regiōes, a situação, embora distinta, aparentemente não é mais animadora. Um exemplo disso é o que ocorre na região Sudeste. Nesta, o número de consultórios públicos ${ }^{3}$ é de 18.631. Mesmo considerando que todos estejam em plena condição de funcionamento e que em cada um deles ocorram o máximo de 32 consultas em 8 horas, isto é, consultas com duração de 15 minutos cada, a capacidade total de atendimento por ano seria de 13.712.416, ou seja, menos de uma consulta anual por habitante apenas da Grande São Paulo, incluindo gestantes, crianças e doentes crônicos que, dentre outros, sabidamente necessitam de acompanhamento muito mais freqüente do que esse.

No âmbito da vinculação administrativa verifica-se que as instituições sem internação são, em todas as regiōes brasileiras, de caráter predominantemente público (Tabela 1). Apenas nas regiōes Sul e Sudeste a diferença numérica entre os estabelecimentos públicos e privados em regime de não internação é atenuada. Nestas regiōes, as características de organização econômico-social e as relações de produção vigentes justificariam o interesse empresarial de investimentos privados, inclusive no âmbito ambulatorial enquanto instância mais precoce, menos complexa e conseqüentemente menos onerosa de controle da força-de-trabalho. Em contrapartida, dentre os estabelecimentos de saúde com internação, identificase a hegemonia da iniciativa privada em todas as regiōes, característica que mais uma vez se acentua nas regiōes Sul e Sudeste. Embora os dados da tabela 2 mostrem um favorecimento quantitativo da proporção entre os leitos hospitalares e a população destas duas regiōes, é importante lembrar que o predomínio do setor privado influencia consideravelmente esta proporção, uma vez que esses leitos, dado o seu alto custo, são proibitivos para a grande maioria da população, fato que torna os recursos públicos altamente disputados e de difícil acesso, além de estarem sempre sujeitos a políticas orçamentárias restritivas. Nas demais regiões, embora a desproporção entre leitos públicos e privados seja menos acentuada, o montante de recursos existentes é menor, aparentemente perpetuando a situação de inacessibilidade semelhante em todas as regiōes. 
Tabela 3

UNIDADES DE TERAPIA INTENSIVA POR ESTABELECIMENTOS DE SAÚDE COM INTERNAÇÃO SEGUNDO AS REGIŌES, BRASIL-1984

\begin{tabular}{|l|l|r|c|}
\hline Regiōes & $\begin{array}{l}\text { Estabelecimentos } \\
\text { com internação }\end{array}$ & UTIs & $\begin{array}{l}\text { Relação } \\
\text { estabelecimento/UTI }\end{array}$ \\
\hline & & & \\
Brasil & 6.861 & 922 & $7 / 1$ \\
Norte & 432 & 29 & $15 / 1$ \\
Nordeste & 1.902 & 118 & $16 / 1$ \\
Sudeste & 2.484 & 503 & $5 / 1$ \\
Sul & 1.297 & 202 & $6 / 1$ \\
Centro-Oeste & 746 & 70 & $11 / 1$ \\
& & & \\
\hline
\end{tabular}

Fonte: Estatísticas de saúde, assistência médico-sanitária, v.9 1984, p.15.

A distribuição geo-política das UTIs pelo território nacional mantém as mesmas características já descritas para as demais unidades de saúde, isto é, uma significante concentração nas regiōes Sul e Sudeste. Evidentemente é nestas regiōes que se encontram o maior número de hospitais $e$, mais do que isso, aqueles cujas caräcterísticas viabilizam a instalação de um centro de tratamento mais sofisticado, atrelado ao aparato tecnológico e conseqüentemente uma assistência mais onerosa em nome dessa complexidade. A proliferação das UTIs mantém, portanto, estreita relação com a concentração do capital que é necessário para sustentá-las e que, em última instância, beneficia-se com ela mais do que a população para a qual se destina, uma vez que não tem contribuído para a alteração do perfil de morbimortalidade regional, fato plausível na medida em que este é determinado pela estrutura econômico-político-social e ideológica vigente.

Em síntese, pode-se afirmar que, dentro do contexto assistencial, as UTIs podem ser consideradas como recursos existentes quase que exclusivamente nas duas regiōes economicamente mais desenvolvidas. $O$ tipo de assistência que privilegiam, volta-se a um perfil nosológico que extrapola o âmbito das doenças com etiologia e patogênese definidas e terapia causal, incorporando uma dimensão de afecções crônico-degenerativas, comportamentais e daquelas decorrentes de causas não naturais (acidentes e violências em suas diferentes manifestaçöes) que 
culminam por serem atendidas no âmbito das UTIs, apesar do caráter não resolutivo e evasivo desta prática. Esse perfil seria compatível com um Sistema que se caracteriza pela absorção dos avanços tecnológicos, pelo aprimoramento dos métodos diagnósticos e terapêuticos, pela absorção dos recursos farmacêuticos e de equipamentos, ainda que todo esse arsenal não produza um impacto epidemiológico condizente com a dimensão assumida pela assistência intensiva.

Identifica-se, assim, uma tendência da medicalização dos conflitos sociais responsáveis, tanto pelo aumento das tensōes sociais e psicológicas, quanto pela ampliação do campo de atuação nos serviços de saúde, inclusive nas UTIs, privilegiando as regiōes mais desenvolvidas num movimento atrelado aos interesses econômico-sociais que condicionam o perfil institucional das práticas de saúde, perpetuando, entretanto, uma infra-estrutura aquém das necessidades assistenciais em seus diferentes níveis de complexidade.

\section{CONSIDERAÇŌES FINAIS}

A identificação da direção que se dará à assistência intensiva levando em consideração tanto a realidade concreta na qual esta prática está inserida como também e, principalmente, as metas que esse movimento propōe atingir e os compromissos de alteração no sistema assistencial que privilegiará, pressupōe pontuar aspectos relevantes do contexto vigente a partir das seguintes considerações:

- existe um contexto de crise econômico-política-social sem precedentes históricos e que segue um ritmo cuja evolução penetra na área do imprevisível;

- o desdobramento dessa crise deliberada induz um grave processo recessivo com mecanismos de ajustes que privilegiam medidas como: inflação corretiva, arrocho salarial, contenção da despesa pública e do crédito, queda do consumo, do emprego, do investimento e do crescimento;

- a vinculação entre esse contexto e a saúde é nítida na medida em que esta extrapola o âmbito biológico, situando-se no interior da organização social da produção, ou seja, na selvageria do capitalismo vigente que se perpetua pela superexploração da força-de-trabalho. Esse projeto organizado e eficiente de manutençăo das condições de pobreza e de marginalização das camadas mais oprimidas da sociedade determina um quadro extremamente crítico, onde se exacerbam as chamadas doenças da miséria (desnutrição, doenças transmissíveis, parasitoses) combinadas às doenças do desenvolvimento (acidentes de trabalho, de trânsito, violência, doenças ocupacionais, intoxicações, afecçōes crônicas não transmissíveis, alteraçōes comportamentais);

- frente a essa demanda o Sistema de Saúde, na sua estrutura político-jurídica, caracteriza-se pela existência de serviços quantitativa e qualitativamente insatisfatórios, apesar do crescimento ocorrido no setor e apesar das tentativas de 
estabelecer um sistema de articulação entre os diferentes segmentos e procedimentos que o estruturam. Além de precária, essa rede de atendimento se caracteriza, também, pela concentração de recursos nas regiōes mais desenvolvidas, fato que não torna tal população mais favorecida por essa concentração institucional;

- esses dados evidenciam a necessidade premente de expansão dos recursos assistenciais, tendo como referencial os princípios da Reforma Sanitária enquanto sistema único estatal de saúde a ser efetivamente redimensionado e articulado em seus diferentes níveis de complexidade, a partir das especificidades dos contextos saúde-doença e dos recursos existentes em cada região.

Frente a essas considerações é possível identificar algumas perspectivas para a prática da assistência intensiva. Nesse sentido, pode-se pontuar duas diretrizes. Num extremo, tomam consistência noçōes de cunho quase que exclusivamente tecnicista. A especificidade desse encaminhamento teria como característica primordial a idéia de peculiaridade. A crise assistencial que atinge inclusive as UTIs decorreria de desarranjos internos enquanto entidade estática e isolada do contexto intra e extra-institucional. Nessa concepção, medidas conjunturais - adequação de planta física, treinamento de pessoal, aquisição de novos equipamentos, dentre outras - seriam capazes de superar o contexto de crise. Teriam como principal objetivo o aperfeiçoamento técnico transformado num fim em si mesmo uma vez que todo o aparato existente não teve o impacto epidemiologico esperado. Nessa concepçāo questōes basais não são sequer consideradas uma vez que ignoram o todo. Nela não são explicitados os referenciais a apontar a sua razão de ser enquanto integrante de um sistema de saúde, ou seja, quais os compromissos, os papéis, as competências e, mais do que tudo, qual seria o perfil de organização de prática a ser privilegiado.

A segunda corrente considera prematura qualquer proposta que sugira novas diretrizes para a assistência intensiva sem antes explicitar as concepções que apontem a direção e o sentido a ser dado a essa prática. Nessa vertente, entender esse contexto é ter condiçōes de formular sua crítica. Conhecê-la é, mais do que tudo, conhecer o todo, estabelecendo vínculos entre a sua situação e os determinantes tanto do processo saúde-doença como também, das diretrizes da prática. Identificar essa situação significa, ainda, inserí-la no interior das relaçōes de trabalho vigentes na Enfermagem e, ainda, na conformação das atividades multiprofissionais delineadas pelos princípios da Reforma Sanitária. Estas deverão ganhar novos contornos e, portanto, novos relacionamentos no caminho da democratização interna e externa das práticas de saúde.

Em síntese, pode-se considerar que os caminhos a serem assumidos pela assistência intensiva articulada aos demais níveis de assistência ainda não estão 
delimitados. Forte é a pressão no sentido de referendar as tendências vigentes, auto limitadas num contexto de tecnicismo enquanto instrumental capaz de alimentar, pela sua existência, uma espécie de assistência experimental pela qual se demonstraria o potencial do aparato de que se dispõe sem que estes efetivamente justifiquem a sua razão de ser.

Entretanto, apesar da força dessa tendência e da sua sintonia aos interesses econômicos que permeiam esta prática, o modelo vigente não pode mais ser considerado como hegemônico. Nesse contexto, pouco resta aos enfermeiros senão tomar consciência da própria existência enquanto profissionais da saúde, identificar seus problemas no sentido de superá-los sem se curvar à dominação de interesses que não os da profissão e da comunidade, desmistificar a imagem de pseudo-competência dessa prática e, mais do que tudo, efetivamente se engajar no processo de transformação do sistema assistencial conforme os princípios da Reforma Sanitária de maneira a garantir: a integralidade da assistência, a universalidade, a descentralização, a eqüidade, a resolutividade e o controle social da população sobre as açōes de saúde.

IDE, C.A.C. \& CHAVES, E.C. The geo-politic distribution of intensive care units in Brazil. Rev. Esc. Enf. USP, São Paulo 23(3):193-204, dez. 1989.

This research presents the course of the health institucionalization process in Brazil and calls attention to the intensive care units in this context.

UNITERMS: Health care systems. Health services. Intensive care units.

\section{REFERÊNCIAS BIBLIOGRÁFICAS}

1 BRASIL. Ministério da Saúde. Secretaria Nacional de Programas Especiais de Saúde. Divisāo Nacional de Doenças Crónico-Degenerativas. Bases estratégicas e operacionais. Brasília, 1986, 19 p. (mimeografado).

2 CARNEIRO, A.M. Comunicação enfermeiro-paciente na UTI: estudo interativo do processo de comunicação. Rio de Janeiro, 1982, 127 p. (Dissertação de mestrado - Escola de Enfermagem da UFRJ).

3 FUNDAÇÃO INSTITUTO BRASILEIRO DE GEOGRAFIA E ESTATISTICA. Estatística de saúde: assistência médico-sanitária. Rio de Janeiro, 1986. v.9.

4 IDE, C.A.C. Prática de enfermagem em UTI e contexto de saúde, 1988, 9 p. (mimeografado).

5 POSSAS, C.A. Política de saúde e reforma agrária: suas implicaçōes para o currículo de enfermagem. Trabalho apresentado no SEMINÁRIO SOBRE ENSINO SUPERIOR DE ENFERMAGEM DA REGIẤO SUDESTE, 1ํ, São Paulo, 1987. 138 p.

6 SINGER, P. et alii. Prevenir e curar: o controle social através dos serviços de saúde. Rio de Janeiro, Forense-Universitária, 1981, $166 \mathrm{p}$.

Recebido em 21/02/89 